\title{
INSTITUCIONES Y COSTUMBRES ECLESIÁSTICAS EN CERVANTES
}

Cervantes está al corriente de la vida cristiana y presenta en sus obras una gran cultura sobre las prácticas y manifestaciones públicas o privadas de la religiosidad: liturgia, ceremonias, rituales de los sacramentos, procesiones, excomuniones, santuarios nacionales, catequesis infantil, clero con sus atributos y atuendos, etc.

Es difícil que nuestro autor domine todos estos aspectos eclesiásticos, si no era un cristiano practicante. A un simple o agudo observador, ajeno a la Iglesia, se le escaparían muchos de estos ínfimos detalles. Quizás cumple Cervantes las palabras de don Quijote, en el sentido que el caballero wha de ser teólogo para dar razón de la cristiana ley que profesa, clara y distintamente, adonde quiera que le fuese pedidon (II,18).

Abandono en este artículo la doctrina teológica, la naturaleza de los sacramentos y las innumerables citas bíblicas que utiliza el autor. Sólo aportaré algunos aspectos externos de la religiosidad, cuestiones que estaban en pleno conflicto con la ideología protestante y erasmista.

\section{LA LITURGIA}

El aspecto externo de las celebraciones litúrgicas fue duramente criticado por Lutero y puesto en duda por Erasmo, a favor de un espíritu más intimista o de piedad interior. En efecto, el reformador desprecia todos los ritos en los que ponen su interés los católicos: 
«Ha muerto la Iglesia por el peso de las infinitas leyes referentes a obras y ceremonias; ha desaparecido la fuerza y sabiduria del Bautismo, se ponen cadenas a la fe de Criston'

Cervantes anota, por su parte, muchas de las ceremonias litúrgicas sin criticarlas. El cautivo, que trae de Argel una mora, que no se ha bautizado "sin que supiese primero todas las ceremonias que manda nuestra Santa Madre la Iglesia» (I,37). En el Persiles se hace bautizar a Ricla en un río "sin las ceremonias debidas" por falta de sacerdote e Iglesia (I,VI). El Concilio acepta el agua natural en estas ocasiones ${ }^{2}$.

El escudero Sancho, que cita siempre los sermones del cura de su pueblo, pronuncia en un contexto peculiar la expresión del Bautismo «abrenuntio», fórmula con la que se renuncia a las pompas y obras del diablo.

La penitencia de carácter ascético que hizo don Quijote en Sierra Morena (I,26-27), o la que hace Sancho en su gobierno de la Ínsula con disciplinas y rezos (II,5), pertenecen a estas prácticas de mortificaciones, sacrificios voluntarios y flagelaciones en actos públicos o procesiones penitenciales, propias de la vida ascética y muy corrientes en la antigüedad. En esta misma época, las aconseja San Ignacio de Loyola en sus Ejercicios Espirituales ${ }^{3}$ y todos los autores ascéticos y místicos de España y Europa.

Pero, Cervantes conoce también la confesión de los pecados, práctica visible del Sacramento de la Penitencia: el ermitaño busca confesor $(I, 26)$; la muerte fingida de Basilio y la actuación del cura (II,21); consejo del ama a don Quijote para que se confiese a menudo (II,73); varias peticiones de confesión del caballero en trance de muerte (II,74), a quien después de confesarle wordenó su alma con todas las ceremonias que se requieren", aludiendo sin duda a la Extremaunción, Comunión y Recomendación del alma.

Un tal Saavedra (que al parecer es Cervantes) anuncia en $E l$ trato de Argel las condiciones del verdadero arrepentimiento: "Contrición de corazón, confesión de la boca, satisfacción de obras». Por parte del sacerdote se exige el "sigilo" sacramental. El cura «no hablará más que un mudo» dice el autor; por su lado el con-

1 Lutero, Obras Completas, Ed. de Teófanes Egido, Salamanca, Ed. Sígueme, 1987. El texto es de la Cautividad Babilónica, p. 119. Por aquí citaremos siempre.

2 F. LOPEZ DE AYALA, El Sacrosanto y Ecuménico Concilio de Trento traducido al castellano, París, Libr. Rosa y Bouret, 1857, nueva edición, p. 91. Por aquí citaremos siempre.

${ }^{3}$ IGNACIO DE LOYOLA, Obras Completas, Edic. de Iparraguirre y Dalmeses, Madrid, BAC, 1963, 2. ed., pp. 216-217. Por esta obra citaremos siempre. 
fesor asegura: «Mi profesión es guardar secreto» (II,1). En El licenciado Vidriera reprocha la conducta de los borrachos.

«Sabe cada uno de vosotros mas pecados que su confesor, más con una diferencia: que el confesor los sabe para tenerlos en secreto, y vosotros, para publicarlos en las tabernas».

A la confesión sigue la penitencia que se impone por los pecados (I,23), que coincide con la doctrina ignaciana (o.c., p. 200) y con el mandato de Trento (Ayala, o.c., p. 160).

Las ceremonias de la Misa y su obligación de asistencia los domingos y fiestas, son ampliamente citadas por Cervantes, así como algunas prácticas populares en torno a este Sacramento de la Eucaristía, en plena contradicción con el Protestantismo. Cervantes no fue acusado por la Inquisición por expresar sus ideas de "Misa diaria» (II,16), como lo fue Francisco de Osuna por su libro Gracioso convite, donde se recomendaba la comunión diaria 4 . El mismo Ignacio se refiere al "pelegrino» de Alcalá, quien se quejaba de la Inquisición, a causa de un sacerdote que no le quería dar la comunión "porque se comulgaba cada día» (o.c., p. 121).

Tales sospechas proceden de las ideologías protestantes, de Erasmo e, incluso, de autores católicos que pedían una mayor frecuencia de los Sacramentos.

La práctica y costumbre de ofrecer misas y limosnas por los fieles difuntos, aparece frecuentemente en las obras de nuestro autor. El más significativo es el episodio y el diálogo de don Quijote con Sancho que había caído en una hondonada o sima. Ante las voces de éste, Cervantes mezcla la narración profana con la vena de la espiritualidad católica. Don Quijote repite varias veces, que si está en el otro mundo, y más en concreto en el Purgatorio: "sufragios tiene nuestra madre la Santa Iglesia Católica Romana bastantes a sacarte de las penas en que estás, y yo, que lo solicitaré con ella, por mi parte, con cuanto mi hacienda alcanzare" (II,55). En otros muchos lugares, como en El trato de Argel, Pedro de Urdemalas, Rinconete y Cortadillo, Rufián dichoso, Cervantes sostiene la creencia, a través de sus personajes, que es bueno ofrecer sufragios por las almas de los que padecen temporalmente en el Purgatorio y que no pueden ayudarse por sí mismos.

4 Tercer abecedario espiritual, Edic. de Melquiades Andrés, Madrid, BAC, 1972, p. 105. 
Esta doctrina está a favor del Concilio de Trento y en contra de las teorias de Lutero. El reformador niega rotundamente el carácter sacrificial de la Misa:

«De ahi nace ese error evidente e impío de ofrecer y aplicar la misa por los pecados, por las satisfacciones, por los difuntos o por cualquier necesidad propia o ajena... La misa es una promesa divina que no puede aprovechar a nadie, ni socorrer a nadie, comunicarse a nadie, sino sólo al creyente y en virtud de su propia few (La cautividad, o.c., 105).

Cervantes sigue al Concilio que afirma este carácter de sacrificio:

«No sólo se ofrece con justa razón por los pecados, penas y satisfacciones y otras necesidades de los fieles que viven; sino también, según la tradición de los Apóstoles, por los que han muerto en Cristo sin estar plenamente purgados" (Ayala, pp. 243-244; el canon III excomulga a los que no acepten esta doctrina, p. 249).

La fea costumbre de los ricos en los atuendos y asientos principales en las iglesias, es criticado por Cervantes, al constatar el supuesto comportamiento de Teresa Panza en el templo (II,5). Del mismo modo, se alista a la doctrina conciliar al no ver con buenos ojos el privilegio de algunos potentados que oyen misa en un suntuoso oratorio privado en su propia casa $(I I, 49)$. Ambas situaciones estaban condenadas por Trento (Ayala, pp. 251-253).

También el matrimonio cristiano e indisoluble goza de algunas ceremonias especiales y necesarias: se debe hacer ante la "haz" de la Santa Iglesia Católica Romana (II,48); debe ser celebrado por un sacerdote (I,26; II,21, etc.). Todo ello coincide con las disposiciones de Trento (Ayala, pp. 307-308). Cervantes, en sus novelas, tiene cuidado que los noviazgos lleguen al matrimonio canónico, a fin de evitar las uniones clandestinas. Para ello son necesarias las amonestaciones proclamadas por tres veces en la Misa Mayor, con los nombres de los contrayentes. (Ver La gitanilla, El casamiento engañoso, El amante liberal, etc.).

Para evitar estos matrimonios whechos a hurtadillas" (Persiles, III,VIII), son necesarias además la presencia de testigos, consentimiento mutuo ante los presentes, el lazo al cuello, el paño del yugo, la unión de las manos y otras ceremonias (Ver I,11; I,19; II,21; Persiles II,XXI, etc.). Todos estos ritos y señales externas son las recomendadas por Trento. La Galatea habla de las «ceremonias acostumbradas" en los matrimonios (Lib. III). En La fuerza de la sangre Cervantes se refiere a la validez de un casamiento sin los ritos del Concilio, porque no se conocían aún; en estos casos sirve solamente la voluntad de los contrayentes y la 
presencia del cura usin las diligencias y prevenciones justas y santas que ahora se usan"; estas palabras aluden a los ritos tridentinos antedichos para evitar las uniones ilegales. En el mismo sentido, Pedro de Córdoba prohibía a los indios el «matrimonio a hurtadillas y sin las ceremonias acostumbradas", siguiendo toda la tradición del siglo XVI ${ }^{5}$.

Cervantes no sólo se refiere a ritos concretos, sino a las ceremonias en general, contra la posición protestante. Los peregrinos del Persiles alaban las "católicas ceremonias de Lisboa" (III,I) y las de Toledo, "espejo y depósito de católicas ceremonias" (III,VIII). Cervantes debía conocer la complejidad de las liturgias monacales, catedralicias y vaticanas; por eso, en una ocasión, parece criticarlas por su gran barroquismo, cuando Auristela reza en Lisboa «sin las torcidas ceremonias de la Iglesia» (Persiles, III,I). Con ello se alaba la libertad e interioridad de la oración, resabio erasmista, pero sin menoscabo de lo dicho anteriormente.

Otras muchas prácticas del ceremonial cristiano popular aparecen en Cervantes, como el "santiguarse" y "persignarse", primera señal que aprenden los niños $(I, 8 ; I I, 28 ; I I, 29)$. Da cuenta de la "bendición" de elementos y de comidas $(\mathrm{I}, 17 ; \mathrm{I}, 47)$, de las ceremonias de exequias (I,13 y Persiles III,I); se conocen los ritos de los exorcismos, incluso con sus palabras latinas: «Fugite partes adversas" (II,42), "vade retro", «Exi foras" (Pers. III,IX. III,XXI), o simplemente «abrenuntio" (R. y C.). Estas fórmulas sirven para expulsar demonios (CP), o alejamiento de fantasmas, como las que hizo el sacerdote en La Galatea, "con sagradas vestiduras" y con «lícitos y acomodados exorcismos" (Lib. II), o como los que utilizaban los clérigos con una cruz, hisopo empapado en agua bendita y lectura de los Evangelios (Pers. III,II). De este modo se practican los exorcismos contra la bruja Cañizares (CP).

Algunas ceremonias se realizan en los templos. En él se recibe a la recién parida con el niño (Git.); las canonizaciones de los santos en la Basílica de San Pedro (CP y LV). Por su estancia en Roma y servicio a un eclesiástico (más tarde cardenal), Cervantes asistió a las ceremonias del Papa vestido de Pontifical. Conoce el color morado del atuendo cardenalicio y el "cambio de las capas" de estos dignatarios según el Ritual Romano (I,21 y $\mathrm{CP}$; alude a las estaciones romanas de Cuaresma (Pers. IV,III; IV,VI).

Igualmente hace referencia a la celebración solemne de la Misa en el día de la Resurrección del Señor en medio de la mo-

5 Doctrina para la instrucción de los indios, México, 1544 y 1548, Edic. de Miguel A. Medina, Salamanca, Ed. San Esteban, 1987. 
rería (Los baños de Argel, jorn. III), la ofrenda de Todos los Santos (RC), las novenas (CAE), los siete viernes anteriores a Pentecostés y los jubileos que se ganaban dentro del monasterio (EI), o el jubileo de Roma del año 1600: «que es el centésimo que se usaba" (pers. III,XII), o las estaciones del Vía Crucis y los viernes de Cuaresma (EI).

Otras ceremonias se celebran fuera del templo, como la procesión del Corpus con su mayordomo (AL) y con su monumento (CP); alude a los "autos del Corpus" $(I, 12)$ y al "auto de la muerte" de Lope de Vega (II,11) y a las "Danzas de la muerte" $($ II,12). En cierta ocasión recuerda el lavatorio de los pies que los Reyes de la Casa de Austria practicaban con doce pobres, al estilo de Cristo en la Última Cena, a los que daban un «serón» de objetos (CS).

Fuera o dentro de la iglesia se podían rezar "Las Horas de Nuestra Señora" (CAE), devocionario similar al Breviario sacerdotal; la colocación de una cruz sobre la tumba de un cristiano (Pers. I,V). Con frecuencia se citan frases litúrgicas acomodadas a un interés jocoso, pero no irreverente, aunque la Inquisición portuguesa prohibió más tarde algunas de ellas: "Sicut erat in principio" (I,46; II,71; RV); "Por los siglos de los siglos. Amén" (II,1 y AL). Se mencionan los "Quiries", como signo de algo muy largo, sobre todo si se canta en Gregoriano (RC). Se cita la frase "Tu autem de todo" (CE), aludiendo a la antífona que se recita al final de las Lecciones del Breviario: "Tu autem, Domine, miserere nobis». No obstante el templo es el lugar donde se celebran las mejores ceremonias:

"Estando un día en la iglesia vio que traían a enterrar a un viejo, a bautizar a un niño y a velar a una mujer, todo al mismo tiempo, y dijo que los templos eran actos de batallas, donde los viejos acaban, los niños vencen y las mujeres triunfan» (Licenciado Vidriera).

Otros muchos elementos de la vida eclesiástica o de la devoción popular, son anotados por Cervantes, que superan un contacto superficial con la Iglesia: Las "carnes tolendas", o supresión de la carne en Cuaresma (I,17); las "Bulas de composición", o restitución de los bienes ajenos cuyo dueño se desconoce (I,19); las "Cartas de descomunión", referentes a las de Paulo III, que conminaban a los que retuviesen cosas ajenas (RC; IF); los «Participantes", o los que tratan con excomulgados notorios $(I, 19)$; varias veces cita "la Santa Hermandad", como institución terrorífica (I,23; II,43, etc.); las "Profesiones de religiosas", con la presencia de la comunidad, del Provisor del convento, del Vicario, del Obispo y otros señores principales (EI). 
Igualmente nos da noticias de las cofradías y cargos que las componen: "Prioste», hermano mayor de la Cofradía (I,21; II,43; JD); "Muñidor", criado que avisaba a los cofrades para algún acto o reunión; "Disciplinantes de Luz», miembros de una cofradía que llevaban cirios en una procesión, en contraste con los «Disciplinantes de sangre» que se azotaban (II,35); nos informa sobre las multas que se imponían a los cofrades que no asistían a los actos, cuyo importe se empleaba en cirios (II,14). Solamente Rinconete y Cortadillo, y El rufián dichoso, ofrecen innumerables datos de estas costumbres y prácticas religiosas.

\section{ALUSIONES A LOS ESTUdiOS TEOLÓGICOS}

No son estas las únicas manifestaciones eclesiásticas que aparecen en el Manco de Lepanto. El autor ha rastreado todos los entresijos de las universidades, monasterios e iglesias. Es fácil hallar referencias a conceptos, términos teológicos, que eran objeto de las discusiones de escuelas y alumnos de los siglos de oro.

En efecto, Don Diego de Miranda se queja de que su hijo se negó a estudiar leyes ni otras ciencias, "ni la reina de todas, la Teología" (II,16). Tal concepto pertenece a la Escolástica, a partir de Santo Tomás de Aquino, en el que la Teología es la reina y las demás ciencias son las «ancillas" (sobre todo la Filosofía). Sor Juana Inés de la Cruz (1651-1695) intentó penetrar en todos los saberes para ilustrar la fe y las Sagradas Escrituras. Daba sus razones:

«Porque ¿cómo entenderá el estilo de la reina de las ciencias quien aún no sabe el de las ancillas?" 6

La frase "gratis data» es otro de los conceptos escolásticos, que en Cervantes se utiliza en sentido acomodaticio (II,71). En la clasificación de las "gracias", Santo Tomás las dividía en "gratis gratum faciens" (la gracia santificante del Tridentino) y "gratis data" (dada gratuitamente o carismas no necesarios para la salvación, sino para beneficio de la comunidad) ?.

${ }^{6}$ Citada por A. CASTro en De la edad conflictiva, Madrid, Taurus, 1952, p. 160.

7 Summa Theologica, I.-II., q. III, aert. 1. Ver también Vacant-Mangenot, Dictionaire de Theologie Catholique, vol. VI, col. 1558 (grace). 
Como ejemplos de la época habría que citar a Francisco de Osuna $^{8}$ y a San Ignacio de Loyola ${ }^{9}$, que utilizan a menudo esta terminología.

Morón y Green atribuyen a Cervantes un espíritu escolástico en su arte narrativa, pues posee la misma visión de Dios, del mundo y del hombre que confesaba la Teología Escolástica. De este modo, el siglo XVI sería una síntesis tomista que Melchor Cano y su compañero Soto se encargarían de difundir ${ }^{10}$. En el mismo ambiente Ignacio de Loyola ordena a los Padres de Alemania que sería necesaria una "Suma de Teología Escolástica", y recomendaba que no se la mirase con desdén por los eruditos actuales, aludiendo a Lutero que la despreciaba (o.c., p. 883).

En otras ocasiones, cita frases estereotipadas que utilizaban los estudiantes de las universidades y seminarios en los ejercicios públicos, disputas escolásticas que han llegado hasta poco antes del Vaticano II. Por ejemplo:

«Bien podrá ser ello así, pero dubitat Agustinus» (II,50).

Del mismo modo, está al corriente de los teólogos famosos y de sus obras. Alude a la gran extensión de los escritos del Tostado (II,3): «pudiera hacer un volumen mayor, o tan grande, que el que pueden hacer todas las obras del Tostadon, refiriéndose a Alfonso Tostado Ribera, obispo de Ávila y prolífico escritor de tratados teológicos. En otra ocasión señala las «Súmulas de Villapando" (I,47), catedrático de Alcalá, que en 1557 escribió la «Summa Summularum», libro de texto en muchas Universidades.

Los grados universitarios eran civiles y eclesiásticos a la vez. En el Quijote se dice que el cura del Toboso kera hombre docto y graduado en Sigüenza", lo que supone una ironía sobre sus escasos conocimientos, pues era una "universidad menor" $(\mathrm{I}, 1)$. Don Quijote también se refiere a un caballero andante, que kasí se paraba a hacer un sermón o plática en mitad de un campo real como si fuese un graduado por la Universidad de París» $(I, 18)$, como centro de estudios importante y famoso.

Sería prolijo enumerar aquí los diez mandamientos de la Ley de Dios, procedentes de la Biblia y los cinco procedentes de la ley eclesiástica, como ayunos, obligación de oír misa, diezmos y primicias. Todos ellos aparecen en las obras de Cervantes.

8 Tercer abecedario espiritual, o.c., p. 351.

9 O.c., pp. 723 y 727.

10 C. Morón ARroyo, Nuevas meditaciones del Quijote, Madrid, Gredos, 1976, 2.: ed., pp. 58-94. Las pruebas escolásticas las adujo O. GreEN en España y la tradición occidental, Madrid, Gredos, 1965, 4 vol. 
Aquí quisiera referirme al lugar donde aparecen estos mandamientos y la esencia moral y de prácticas de la doctrina cristiana: el catecismo, al que Cervantes llama "Christus». Según Rodríguez Marín y Riquer, en sus ediciones del Quijote, se trata de las cartillas que llevan una cruz en la portada precediendo al abecedario. No solamente, a mi parecer, era una cartilla para aprender a leer, sino también, y sobre todo, un catecismo de doctrina cristiana. Unas palabras de Sancho nos revelan este sentido:

"Letras pocas tengo, porque aún no sé el abecé; pero bástame tener el Christus en la memoria para ser un buen gobernador" $(\mathrm{II}, 42)$.

Sancho opone el «abecé» (saber leer) y el "Christus" (catecismo que contiene los preceptos para gobernar con justicia cristiana). Clemencín interpreta en este sentido el pasaje: "Le importa más (a Sancho) tener a Dios presente, que tener muchas letras\%. A ello habría que añadir el testimonio de Alonso de Ledesma (1607):

«Sabe leer lo primero,

porque quien al Christus llega

todas las letras conoce,

pues en Dios todo se encierra" ${ }^{\prime \prime}$.

Ximénes Patón apoya también nuestra tesis:

«El maestro christiano que enseña a leer a los niños. Lo primero que enseña y nombra es este divino y celestial carácter, y mostrando la señal de la cruz, le nombra Iesus Christusi ${ }^{12}$.

Esta enseñanza se da a los llamados "niños de la doctrina", tantas veces nombrados por Cervantes y autores de la época. En el Quijote se alude, con cierta exageración, a los 1.300 azotes, que «no hay niño de la doctrina, por ruin que sea, que no se los lleve cada uno" (II,35). Sancho nos da la noticia de que se hace una gran obra de caridad recogiendo a doncellas o kniñas de la doctrina" (II,40). Sobre las solemnes y difíciles palabras que un enamorado dirige a la fregona, un oyente comenta: «Más es para decirlo a un niño de la doctrina que a una fregona" (La ilustre fregona). En el Rufián dichoso se advierte: «Eres más sonado y más mocoso que un niño de la doctrina».

El mismo Cervantes lo reconoce por boca de Pedro de Urdemalas:

1 Conceptos espirituales. Segunda parte, cit. por MARÍn, ed. crítica, vol. VI, p. 226.

12 Epitome de la ortografía latina y castellana, cit. por MARIN, vol. VI, p. 226. 
«Pero sé decir que fui de estos niños de la doctrina, sarnosos que hay por ahí.

Alli, con dietas y azotes que siempre sobran alli, aprendí las oraciones» (Jorn. I).

Otro texto de Jerónimo Quintana, que cita Marín, nos confirma lo que intentamos probar:

"En el Colegio de San Ildefonso, Arzobispo de Toledo, se crían niños que llaman de la Doctrina, por enseñarles en él con mucha caridad a leer y escribir, informándoles en buenas costumbres y principalmente lo tocante a los rudimentos de la doctrina cristiana y conocimiento de los misterios de nuestra fen.

Se enseña a leer y escribir, obra primera de la Iglesia que amó siempre la cultura, pero "principalmente», dice Jerónimo, la "doctrina cristiana" y los "misterios de nuestra fe». Estas escuelas son instituciones para leer y creer. San Ignacio, que fundó tantos colegios para la juventud, los llama "niños de la doctrina» (o.c., p. 913 y otros lugares) o «ir a la doctrina» a los pequeños que acuden a la catequesis parroquial. Las sierras de la alta Extremadura, aisladas hasta hace poco tiempo, hablan todavía con refranes al estilo de Sancho, o utilizan arcaísmos que aparecen en Cervantes (como «ñudo" por «nudo», etc.). Allí, pues, ha quedado el sentido de uniños de la doctrina" como niños que asisten a las clases de catecismo.

\section{El ESTAMENTO CLERICAL}

Solamente en el Quijote hay una Iglesia jerárquica en miniatura, según Hatzfeld ${ }^{13}$. Se proponen varios eclesiásticos que ayudan a don Quijote para que sane de sus locuras: El Bachiller Sansón Carrasco, el cura del Toboso, el capellán de los duques y el canónigo de Toledo. Cervantes se mueve con facilidad en este mundo de Iglesia y conoce perfectamente las clases de órdenes sagradas, el celibato de estos ministros, el hábito clerical y su dignidad frente a los laicos. Todo ello son elementos propios de la tradición eclesiástica refrendados por el Concilio de Trento.

El cura $(1,6)$, el canónigo $(I, 29)$ y el Bachiller Sansón Carrasco $(I I, 3)$ juraban a menudo «por las Órdenes que recibí" o "por el

${ }^{13}$ El Quijote como obra de arte del lenguaje, Madrid, CSIC, 1966, p. 134. 
hábito de San Pedro que visto", al defender cualquier doctrina u opinión, apoyándose en este rango de "ordenado».

Cervantes conoce y cita todas las órdenes Sagradas, excepto el Diaconado. Teresa Panza notifica a su marido que "el hijo de Pedro el Lobo se ha ordenado de grados y corona, con intención de hacerse clérigo" (II,52). La "corona" o "primera tonsura" (según Los alcaldes de Daganzo), es una rapadura en forma de corona en la cabeza; no es propiamente "orden" sino el ingreso en la carrera eclesiástica. Los "grados" son las cuatro órdenes menores, que el Bachiller reconoce tenerlas: "no tengo otras órdenes que las cuatro primeras" (II,3); se llaman cuatro órdenes menores: acólito, exorcista, lector y ostiario. "Clérigo" es ya el estado sacerdotal, que otras veces se denomina "licenciado». La guarda cuidadosa alude al "grado de Epístola", refiriéndose al Subdiaconado. En cambio, el enlutado caído dice: «Soy licenciado y tengo las primeras órdenes" $(I, 19)$. Sancho hace referencia a las "Órdenes Arzobispales" $(\mathrm{I}, 29)$ a propósito de don Quijote que deseaba llegar a tal estado. Probablemente quiere decir "episcopales», que confunde las cosas debido a su ignorancia.

La ordenación exige un privilegio: el de la Inmunidad. Cervantes está obsesionado con él, quizás porque el clero se apoyaba constantemente en él ante cualquier agresión anticlerical. Se llama "privilegium Canonis" porque responde al canon IV del Concilio Lateranense II (año 1139), donde se concede al clero tutela jurídica contra cualquier violenta o injusta agresión real, a la vez que se excomulga a los tales y prohíbe a los obispos absolver a los agresores, a no ser en caso de muerte ${ }^{14}$. El enlutado caído al suelo por don Quijote, invoca este privilegio, citando el comienzo del canon IV en latín:

"Olvidábaseme decir que advierta vuestra merced que queda descomulgado por haber puesto las manos violentamente en cosa sagrada juxta illud: "Si quis suadente diabolo, etc."" $(\mathrm{I}, 19)$.

Don Quijote (Cervantes en cualquier caso) sabe que no se puede agredir a un sacerdote o clérigo menor. Con cierta ironía responde:

"No entiendo ese latín, mas yo sé bien que no puse las manos, sino este lanzón; cuanto más, que yo no pensé que ofendía a sacerdotes ni a cosas de la Iglesia a quien respeto y adoro como católico y fiel cristiano que soy, sino a fantasmas y vestigios del otro mundow $(I, 19)$.

14 El canon puede verse en J. D. MANSI, Sacrorum conciliorum collectio, Graz, Akadem-Druchk-u-Verlanganstalt, 1961, vol. 21, p. 530. 
También el Concilio de Trento se acoge a este "privilegio del foro eclesiástico" en todas las órdenes desde la tonsura hasta el episcopado, y pide a los reyes y príncipes que se respete "la inmunidad de la Iglesia y personas eclesiásticas" (Ayala, pp. 281 y 425-426).

El principio es propio de una sociedad teocrática y plenamente clericalizada. El ladrón de Rinconete teme llevarse una bolsa "porque si es que vuestra merced tiene alguna orden sacra, parecermehía a mí que había cometido un incesto o sacrilegion. El sacristán de Los alcaldes de Daganzo invoca el principio porque es "presbiter" "o de primera tonsura que es lo mismo"; cuando se le intenta mantear reitera su derecho:

\author{
«...Por San Pedro \\ que quedan descomulgados todos cuantos \\ han tocado la mantax.
}

Otro sacristán de la Guarda cuidadosa tiene una pendencia con un soldado, y a pesar de que el sacristán asegura que es "motilón" y que no tiene ninguna orden, el soldado se encoleriza: "Váyase de aquí, señor sotasacristán, que por haber tenido y tener respeto a las órdenes que tiene, no le tengo yo rompido el casco... voto a tal que os tengo que horadar, aunque tengáis más órdenes que un ceremonialn.

Cervantes queda libre de toda sospecha de anticlericalismo como pretende A. Castro de los años veinte y el novísimo Vicente Gaos. Para don Américo todo es ironía cuando nuestro autor toca cualquier punto sobre el tema clerical:

"Tras de lo eclesiástico, Cervantes nota ausencias de espiritualidad cristiana. De ahi sus bormas sobre frailes, clérigos y ermitaños, o sobre las innumerables oraciones ${ }^{15}$.

A continuación aporta numerosos textos en los que Cervantes se enfrenta a las jerarquías sociales de su tiempo, tanto seculares como eclesiásticas. Para él son signos de anticlericalismo la arremetida contra los frailes Benitos ( $(, 1-8)$, escena bien acogida por el público según palabras del Bachiller Carrasco pronunciadas diez años después (II,3); de aquí deduce Castro la crítica al poder "gigantescon y no religioso de las Órdenes monásticas. El eclesiástico de la casa de los duques ejemplariza la oprimente prepotencia (II,31). En la aventura del cuerpo muerto, se ataca una vez más la opulencia eclesiástica, de cuya fiambrera bien repleta

15 Hacia Cervantes, Madrid, Taurus, 1967, p. 300. 
comen también don Quijote y Sancho $(\mathrm{I}, 19)$. El canónigo que acompaña a don Quijote, servido por hombres a caballo, o la misma palabra "canongía", son signos de riquezas sin esfuerzo. La aventura de los disciplinantes $(\mathrm{I}, 52)$ y otros muchos sucesos de la genial novela, indican la aversión de Cervantes a todo lo clerical. Sólo concede algún valor al cura Pero Pérez, hombre simple y vulgar, y al canónigo por su cultura secular y sentido crítico. Tales ataques se deben a su carácter erasmista y de judío converso ${ }^{16}$.

Según Sánchez Albornoz la sátira clerical no pertenece a estos signos sino que ya estaba presente en la literatura anterior, no sospechosa de judaísmo ${ }^{17}$, como ocurre en Rimado de palacio del canciller Ayala, o en el anónimo Libro de miseria de omne, o en el Corbacho del Arcipreste de Talavera, o en el Speculum humanae vitae, de Rodrigo Sánchez de Arévalo y otros. Sánchez Albornoz fue el mejor crítico a muchos presupuestos de Castro ${ }^{18}$.

Vicente Gaos recorre los rasgos anticlericales de Castro y algunos más. Para él todo es ironía, sátira hiriente, desprecio, relajación, vida regalada de clérigos y ermitaños, etc. Así concluye:

«En el Quijote se citan diversas Órdenes religiosas, mas ni una sola con elogion ${ }^{19}$.

No opinan lo mismo otros autores, con toda razón. El mismo Bataillon, que atribuye cierto erasmismo a Cervantes, asegura que no lo buscará en las bromas anticlericales. Sin negar el catolicismo de Cervantes, reivindica "ese sentido del humor" que está presente en tales escenas, supuestamente anticlericales. Cervantes era un cristiano sincero, "creyente ilustrado", que ríe y sonríe ante muchas cuestiones de la vida popular, pero no como los erasmistas de antaño ${ }^{20}$.

Según mis datos, el anticlericalismo de Cervantes es sólo aparente, y en los pocos relatos que existe se dirige a los vicios, pecados o prepotencia del clero y no a la sagrada institución del sacerdocio, a la que respeta y cuya "dignidad" reconoce. Cervantes, a lo sumo, es testigo de una realidad existente de anti-

${ }^{16}$ Ideas repartidas en todas sus obras. Véase también «Cómo veo ahora al Quijoten (Estudio preliminar a la ed. del Quijote del Magisterio Español), 1971, pp. $20,69-71,83$, etc.

17 España, un enigma histórico, Barcelona, Edhasa, 1973, 4.: ed., vol. I, p. 72.

18 Ibid., vol. I, pp. 358-364.

19 Don Quijote de la Mancha, Madrid, Gredos, 1987, 3 vols. (ver vol. III, pp. 122-123, cita en p. 133).

20 Erasmo en España, México-Buenos Aires (ed. francesa: 1937 y española: 1950) (véase especialmente vol. II, pp. 404, 409, 419, 423-425, etc.). 
clericalismo, tan español, precisamente porque el pueblo estaba muy ligado a la Iglesia y percibía con claridad los malos ejemplos de algunos clérigos. Como se ha dicho, los fieles andaban siempre detrás del clero, con palos o con velas.

Ya citamos la postura de don Quijote en la aventura de los enlutados; él pensaba que no ofendía a sacerdotes y a cosas de la Iglesia a quien adora y respeta $(\mathrm{I}, 19)$. El tan traído y llevado ataque de don Quijote al eclesiástico de la casa de los duques, es cierto y virulento, pero hay que atender al contexto: don Quijote es tocado en su amor a la caballería, pero responde respetuosamente:

«El lugar donde estoy, y en la presencia en quien me hallo, y el respeto que siempre tuve al estado que vuestra merced procesa, tienen y atan las manos de mi justo enojon (II,32).

Don Quijote critica, pues, su mal comportamiento y el desprecio de su caballería. Según el retrato que se hace de él en II,31, el eclesiástico carece de los modelos de la discreción y tacto. Carece de prudencia, fortaleza, justicia, caridad, magnanimidad. No es por tanto virtuoso. Cervantes, al criticarle, salvando su dignidad, lo que hace es colaborar con el Concilio de Trento, que pinta la verdadera figura del clero.

Los sacerdotes y los obispos deben ser «irreprochables, sobrios, castos y muy atentos al gobierno de sus casas, sobrios en la mesa y manjares, no pendencieros, no soberbios, ni dados a los deleites" (Ayala, pp. 26-27). También en la sesión IV se condena a los sacerdotes que wandan vagando en diversas cortes, o se detienen en agenciar negocios temporales" (Ayala, p. 83).

El Concilio expone en varios lugares más la figura del buen sacerdote: Que no reprendan a los legos, que den buen ejemplo en su trato y en sus palabras, que no den ninguna clase de escándalos (Ayala, pp. 180-181); que son pastores y no verdugos, que no procedan como señores con los demás, que se consideren hermanos de todos (Ayala, p. 137). Pero hay un texto del Concilio que parece calcado por Cervantes a propósito del eclesiástico. Nótense los subrayados:

"Trabajando con sus exhortaciones y avisos... y reprenderles con bondad $y$ paciencia, pues en muchas ocasiones es más eficaz con los que se ha de corregir, la benevolencia que la austeridad [aspereza], más con la caridad que el poder... y de la suavidad con blandura: para que procediendo sin aspereza.... (Ayala, p. 137). 
Don Quijote hace un comentario sobre la actitud del eclesiástico, que tiene como fuente el texto citado:

\begin{abstract}
"Las reprensiones santas bien intencionadas, otras circunstancias y otros puntos piden; a lo menos el haberme reprendido en público y $\tan$ ásperamente ha pasado los límites de la buena reprensión, pues las primeras mejor asientan sobre la blandura que sobre la asperezai (II,32).
\end{abstract}

El eclesiástico, pues, no es humilde, ni sobrio, lleva una vida regalada en una casa rica, dado a deleites y comodidad, dedicado a negocios temporales y no pastorales, amigo de pendencias y reprensiones ásperas a don Quijote, que actuó sin bondad y paciencia, con poder $\mathrm{y}$ ataque mezquino, desoyendo las normas conciliares. El hecho de que el Santo Oficio nada dijera de este pasaje, es señal que agradó a las autoridades eclesiásticas, por ser, más bien que un ataque, una colaboración con el Concilio para desterrar los males del clero.

Los personajes eclesiásticos que aparecen en el Quijote son siempre considerados y escuchados en sus decisiones e iniciativas, se escuchan con respeto y se obedecen sus consejos. Sancho cita constantemente palabras del cura de su pueblo; que quien ama el peligro perece en él $(I, 2)$, o que la muerte pisa de igual manera las altas torres de los reyes que las chozas humildes de los pobres (II,20). A pesar de que se fía de los consejos de su amo, acude a su confesor para que se los encaje y recapacite (II,43). El cautivo, que comenta los oficios que van a tomar varios hermanos, dice que "el más discreto» quería seguir a la Iglesia.

Las alabanzas al estado clerical se deben a su "dignidad», palabra clave en el Siglo de Oro para el tratamiento de los clérigos. Don Quijote asegura:

"Que no es razón que yo esté a caballo, y una tan reverenda persona como vuestra nerced esté a pie» $(I, 29)$.

En el suceso de los galeotes, don Quijote manifiesta al cura con cierta ironía:

«A quien mal les ha parecido [soltar a los condenados], salva la santa dignidad del señor Licenciado y su honrada persona, digo que sabe poco de achaques de caballería y que miente como un hideputa y mal nacidon $(\mathrm{I}, 30)$.

Sancho propone en el programa de su gobierno, respetar la dignidad sacerdotal: 
"Pienso... premiar a los virtuosos, y sobre todo, tener respeto a la Religión y a la honra de los religiosos* (II,49).

En el Quijote de Avellaneda se censura a Cervantes por haber criticado a Lope de Vega en el prólogo de su primera parte. Nuestro autor se defiende así:

"No tengo yo de perseguir a ningún sacerdote, y más si tiene por añadidura ser familiar del Santo Oficion (Prólogo de la II parte).

Cervantes sigue los conceptos tridentinos sobre las "personas constituidas en dignidad eclesiástican, de la que trata toda la sesión XXI del Concilio (Ayala, p. 404). Los autores de la época insisten en este título, como Fray Luis de Granada, que rechaza la postura protestante de sacerdocio de todos los fieles y prohíbe usurpar el oficio y dignidad de los sacerdotes, propios de los ministros de la Iglesia Católica ${ }^{21}$.

Las alabanzas al clero son muy numerosas. El Licenciado Vidriera dice que entre los canonizados de los últimos tiempos, no hay ninguno que sea capitán, secretario, conde, marqués o duque, pero sí fray Diego, fray Jacinto, fray Raimundo «todos frailes y religiososw. Cervantes alaba, personalmente, el testimonio cristiano de los Padres Trinitarios que redimían a los cautivos de Argel (Cervantes mismo fue liberado por ellos). En El trato de Argel se da la noticia de la llegada de un navío con estos padres "cristianísimos, amigos de hacer el bien... de ejemplo de mucha cristiandad y gran Prudencian (fray Juan Gil). A continuación se alaba a fray Jorge de Olivar, "de no menos bondad y humano pecho" (Jorn. IV). En Los baños de Argel nombra de nuevo a fray Juan Gil que le rescató a él en 1580, a fray Jorge de Olivar, "prudente varón", y a fray Rodrigo de Arce, "de ánimo noble" (Jorn. III). Ricardo, en La española inglesa se refiere a estos padres, que se quedan ellos cautivos para salvar a los demás:

«Porque a toda esta misericordia y liberalidad se extiende la caridad de estos padres, que dan su libertad por la ajena y se quedan cautivos por rescatar a los cautivos".

Se alaba la vida penitente de los ermitaños (II,24) y su pobreza y bondad (Persiles, II,XIX).

Otro aspecto clerical es el celibato, que Cervantes conoce perfectamente y que legalizó el Concilio de Trento, sobre la base

${ }^{21}$ Compendio de la doctrina cristiana, parte III, cap. 18. 
dè una tradición anterior. Sancho expone sus temores ante la idea de que su amo se haga Arzobispo:

«Para esto será menester que el escudero no sea casado, y que sepa ayudar a Misa, por lo menos» $(\mathrm{I}, 26)$.

El mismo escudero vuelve a referirse a la vida celibataria, cuando él, su amo y los eclesiásticos se pasen al campo a pastorear:

«El cura no será bien que tenga pastora, por dar ejemplo; y el bachiller Carrasco si quiere tenerla, su alma en su palma» (II,67).

Parece que Cervantes concede al Bachiller, ordenado de menores, la posibilidad de tener mujer, aunque "su alma en su palma" (allá se las vea, o recibirá su castigo). En otro lugar parece que Cervantes admite o simplemente conoce que hombres con órdenes mayores puedan casarse. En el Quijote se nos narra el caso de una viuda joven que se enamoró de un "motilón" (fraile lego). Enterado el superior del convento, llamó a la viuda maravillándose de que se hubiera enamorado de un simple motilón, tan soez y bajo:

«Habiendo en esta casa tantos maestros [teólogos], tantos presentados [teólogos sin grado de maestro], y tantos teólogos, en que vuestra merced pudiera escoger como entre peras, y decir: Este quiero, aquéste no quierow $(\mathbf{I}, 25)$.

El mismo Concilio de Trento parece reconocer a clérigos, con legítimo matrimonio, si bien en la sesión XXIV del 11 de noviembre de 1563 se declaró definitivamente inválido el matrimonio de los sacerdotes. Así se aprueba en la sesión XXV:

«No pueden los hijos de los clérigos, que no son nacidos de legítimo matrimonio, obtener beneficio ninguno en las iglesias en donde tienen sus padres algún beneficio eclesiásticow (Ayala, pp. 419-421).

Cervantes parece conocer la práctica de su tiempo, en el que las leyes de Trento no se cumplían al pie de la letra. Los sacerdotes, apoyados en costumbres anteriores al Concilio, evitaban el matrimonio oficial, pero seguian existiendo uniones clandestinas. La protesta y desobediencia se hizo fuerte en el Protestantismo (s. XVI), en la Ilustración (s. XVIII) y en el Modernismo en el siglo pasado ${ }^{22}$. El mismo Concilio defiende la perpetuidad

${ }^{22}$ J. LYNCH, «Crítica de la ley del celibato en la Iglesia Católica del Renacimiento a nuestros díasw, en Concilium, n. 78 (1972), pp. 217 ss. 
del sacerdocio y celibato, condenando con excomunión a los que crean que un sacerdote puede volver a ser laico (Ayala, pp. 269272). No obstante, según muchos Santos Padres, Escritores y Concilios anteriores al s. XII, la Iglesia podía reducir al estado laical a sacerdotes no comprometidos con su vocación pastoral ${ }^{23}$; a ello hay que añadir la práctica actual desde hace algunos años.

Otra costumbre que Cervantes reseña es el «hábito sacerdotal». Aunque nuestro autor llega a decir. "caso es sabido / que no deshace el vestido / lo que hace el corazón" (Los baños de Argel), en el Quijote las vestiduras son un distintivo necesario al clero, como dice Sancho:

"No sería bien que un jurisperito se vistiese como un soldado, ni un soldado como un sacerdote» (II,42).

Cervantes habla de "faldamentos y lobas", o sotanas negras que se usaban fuera del Colegio $(\mathrm{I}, 6$ y $\mathrm{I}, 19)$. Carrasco jura por el hábito de San Pedro que viste (II,3), es decir, sotana, bonete negro y manteo. Los mismos juramentos por su hábito hacen el cura (II,5) y el capellán de los duques (II,42). El traje es muy antiguo, pues San Isidoro se refiere a los "vestimenta" sacerdotales que deben llegar "ad vestigia», o sea "hasta los pies" ${ }^{24}$.

Pero el caso donde Cervantes más se ajusta a los decretos tridentinos sobre el hábito sacerdotal, es el acuerdo del barbero y el reverendo Pérez para lograr la atención de don Quijote y llevárselo a su lugar. El cura se vestiría "en hábito de doncella andante" y el barbero de «escudero" $(\mathrm{I}, 26)$. Así lo hacen y ruegan al caballero que venga con ella a "desfacedle un agravio que un mal caballero le había fechon. Una vez salido a la calle con el atuendo mujeril que le había proporcionado la ventera, siente escrúpulos por la posible desobediencia a las leyes tridentinas sobre la necesidad del hábito. Así lo cuenta el narrador Cervantes:

«Mas apenas hubo salido de la venta, cuando le vino al cura un pensamiento: que haría mal haberse puesto de aquella manera, por ser cosa indecente que un sacerdote se pusiese así, aunque le fuera mucho en ello; y diciéndoselo al barbero, le rogó que trocasen trajes, pues era más justo que él fuera de doncella menesterosa, y él haria de escudero, y que así se profanaba menos su dignidad; y que si no lo queria hacer, determinaba de no pasar adelante, aunque a don Quijote se le llevase el diablow $(1,27)$.

${ }^{23}$ José M. CASTILlo, «La secularización de obispos y sacerdotes en la Iglesia latina antiguaw, en Rev. Catal de Teologia, VIII/1 (1983), pp. 81-111.

24 Etimologías, cap. XXII. 
El cura sigue el principio escolástico que el fin no justifica los medios. El fin era bueno, pero malo el medio de elegir otro hábito distinto del ordenado por Trento, que insiste asegurando que "se muestra en la decencia del vestido exterior la pureza interior de las costumbres" (Ayala, pp. 187-188). También prohíbe el Concilio, debido a su "dignidad" y «honor", no usar "públicamente ropas seculares... poniendo un pie en la Iglesia y otro en el mundo". Descouzis ha tratado con amplitud y maestría el caso del trueque de vestidos ${ }^{25}$.

Damos fin a esta resumida exposición, con la alusión cervantina a los beneficios, según la distribución del Concilio Tridentino (sesiones VII, XIV, XXI, XXIV). Así contesta Sancho si llega a ser escudero de un Arzobispo:

«Suélenles dar algún beneficio simple o curado, o alguna sacristanía, que les vale mucho de renta rentada [renta fija], amén del pie del altar, que se suele estimar en otro tanton $(1,26)$.

De otros muchos aspectos da Cervantes noticia en sus obras. Expone la clase de vida regalada de los Canónigos, por las grandes posesiones de las catedrales (I,3; II,36; II,47), el Breviario u Horas Canónicas que rezan juntos el cura y el bachiller (II,73), la mitra de los obispos que es su honra y adorno (II,16), la función de buenos predicadores en los púlpitos (II,20 y 32).

Sobre la vida de los religiosos, alude a la costumbre de levantarse a media noche para rezar maitines y disciplinarse $(I I, 68)$, al silencio de los monasterios de cartujos (II,18), a la vida que se lleva en los noviciados (II,46; $\Pi, 66)$, y a los votos de virginidad que en ellos se hacen (Persiles, IV,V). Da cuenta de algunas supersticiones populares al ver a un fraile por la calle (II,43).

Un cúmulo de detalles de la vida y costumbres eclesiásticas, como hemos expuesto, no se deben a pura casualidad o a una observación del escritor. Sólo cabe la explicación de un Cervantes cristiano, conocedor, en la práctica, de la liturgia eclesial, de los ritos y ceremonias de todos los sacramentos; poco o nada anticlerical y más relacionado íntimamente con el clero, con la vida conventual y seguidor de los decretos tridentinos sobre estos aspectos.

\section{CELso Bañeza Román}

${ }^{25}$ Paul Descouzis, Cervantes a nueva luz vol. I: El Quijote y el Concilio de Trento, Frankfurt am Main, Klostermann, 1966, pp. 42-60. 